\section{Tratamiento de la criptosporidiosis en pacientes de sida}

El parásito protozoario intracelular Cryptosporidium parvum es la causa frecuente de diarrea crónica en pacientes infectados por el virus de la inmunodeficiencia humana (VIH). Actualmente no se cuenta con ninguna terapia antiparasitaria efectiva para reducir la morbilidad y mortalidad por criptosporidiosis. La enfermedad se vuelve crónica cuando el recuento de linfocitos CD4 llega a menos de $180 / \mathrm{mm}^{3}$. En muchos pacientes de sida, la criptosporidiosis desaparece a medida que la terapia antirretrovírica mejora su estado inmunitario. Sin embargo, en pacientes en quienes falla la terapia y en países en desarrollo donde no hay terapia antirretrovírica disponible, la enfermedad causa diarrea y emaciación. El tratamiento ha sido problemático. La paromomicina, antibiótico aminoglucósido difícil de absorber, tiene cierto grado de eficacia en pacientes de sida. En un estudio de 300 pacientes con criptosporidiosis crónica, cerca de dos tercios mejoraron. No obstante, fueron frecuentes las recidivas y la subsecuente enfermedad biliar. Otros dos pequeños ensayos clínicos controlados con placebo han tenido resultados contradictorios.

La azitromicina, otro antibiótico usado contra la criptosporidiosis humana, ha resultado ineficaz en ensayos clínicos para tratar la enfermedad relacionada con el sida. En la práctica clínica, la azitromicina se ha usado mucho en combinación con la paramomicina para tratar la criptosporidiosis, pero no se han investigado bien la seguridad y eficacia de esa combinación. Con objeto de determinar la eficacia, la seguridad y la durabilidad de un régimen combinado de paromomicina y azitromicina en el tratamiento de la criptosporidiosis relacionada con el sida, se realizó el estudio aquí descrito.

Entre el 1 de octubre de 1994 y el 31 de marzo de 1997 en un hospital de distrito del condado Harris en Texas, se trató con la combinación de paromomicina y azitromicina a pacientes de sida con diarrea crónica (definida como tres o más deposiciones de heces líquidas más de 5 días a la semana por 3 o más semanas) y excreción de oocistos de $C$. parvum. Se seleccionaron 11 pacientes con resultados negativos a otros parásitos que no estaban bajo tratamiento con aminoglucósidos ni macrólidos. Se les administró un régimen de $1 \mathrm{~g}$ de paromocitina dos veces al día y $600 \mathrm{mg}$ de azitromicina una vez al día, por vía oral durante 4 semanas y, luego, paromomicina sola por 8 semanas más. Los síntomas y excreción de oocistos se reevaluaron a las 2, 4 y 12 semanas. Los participantes llevaron un registro diario de la frecuencia y consistencia de sus deposiciones, así como de las dosis de medicamentos antimotílicos. También se monitoreó la posible toxicidad del régimen.

Con excepción de un paciente, todos habían sido tratados anteriormente con zidovudina y cuatro estaban recibiendo terapia antirretrovírica con estavudina, lamivudina e indinavir en diversas combinaciones. Los resultados muestran que a la cuarta semana del régimen de paromomicina y azitromicina, la excreción de oocistos había disminuido notablemente y siguió disminuyendo en las semanas siguientes. La disminución mediana de oocistos fue de $84 \%$ en la segunda semana, $95 \%$ en la cuarta y $99 \%$ en la duodécima. También se redujo notablemente la frecuencia de las evacuaciones. La combinación de medicamentos fue bien tolerada y solo dos de los 11 pacientes descontinuaron la azitromicina debido a dolores de estómago. Dos pacientes con diarrea persistente abandonaron la paromomicina entre las semanas 4 y 12 después de una resolución definitiva de la diarrea. En un tercero también se resolvió la diarrea leve residual y ese paciente abandonó la paromomicina después de completar el estudio. No se observaron interacciones de medicamentos, ototoxicidad ni nefrotoxicidad, ni cambios en albúmina sérica, fosfatasa alcalina, peso o calificación de Karnofsky. Los pacientes fueron seguidos por 30 meses después del estudio. Ocho de los pacientes habían mejorado en cuanto a la diarrea, pero la enfermedad biliar siguió siendo un problema. Los pacientes que continuaron con diarrea tenían coinfección con citomegalovirus o reacciones adversas a medicamentos. Los efectos secundarios fueron pocos y similares a los síntomas de la enfermedad subyacente. Dados los resultados, estaría justificado seguir estudiando el uso de otros agentes antiparasitarios o inmunomoduladores en pacientes de sida que no responden a la terapia antirretrovírica. (Smith NH, Cron S, Valdez LM, Chappell CL, White AC Jr. Combination drug therapy for cryptosporidiosis in AIDS. J Infect Dis 1998;178:900-903.)

\section{Los médicos deben combatir la pobreza para reducir la enfermedad}

Es posible que la pobreza y la desigualdad social sean los factores más importantes de todos los que determinan los estados insatisfactorios de 
salud. Cada día hay más pruebas de que la situación socioeconómica está íntimamente relacionada con la enfermedad. Actualmente la pobreza extrema afecta a más de $20 \%$ de la población mundial y hasta $43 \%$ de los niños del mundo en desarrollo - 230 millones de niños - tienen baja estatura para su edad, mientras que 50 millones tienen peso bajo para su estatura. La malnutrición por carencia de micronutrientes como la vitamina A, el yodo y el hierro afecta a cerca de 2000 millones de personas. La esperanza de vida de una persona promedio en uno de los países menos desarrollados es de 43 años, en contraste con la de 78 años en los países industrializados. El conocimiento de estos datos debe tener consecuencias tanto para la práctica clínica como para la política de salud pública y merece la atención de los médicos. La pobreza absoluta, que implica la falta de recursos necesarios para la supervivencia, se asocia con salud deficiente, especialmente en los países en desarrollo. Durante los últimos dos decenios, el deterioro o el estancamiento económico ha reducido los ingresos de 1600 millones de personas. En los países industrializados, la salud depende en gran medida de la pobreza relativa; es decir, del promedio de recursos al alcance de la sociedad.

La pobreza es un fenómeno multidimensional que puede definirse no solo en función económica, sino social. Si bien es bastante fácil medir la pobreza económica, la medición de la dimensión social -que es más difícil- contribuiría mucho más a entender las causas y consecuencias de la pobreza. Con ese fin se están elaborando índices de privación. La medida sociológica de la pobreza se expresa en la exclusión de los más pobres de la forma de vida mayoritaria de participación social. A pesar de que en 1978 la Declaración de Alma-Ata explicó cómo la salud humana depende de condiciones adecuadas de vida, los gobiernos y las organizaciones de desarrollo la han seguido considerando responsabilidad del sector de la salud y ajena a los esfuerzos de desarrollo. En realidad, la relación entre la pobreza y la salud se puede comprender mejor dentro del marco de la nueva noción de "salud del ecosistema", que ubica a la salud y la pobreza en el nexo del ambiente, el desarrollo y el crecimiento de la población. Los ecosistemas fundamentan la salud pública en cualquier tipo de país, no solo porque se relacionan con la producción de alimentos, sino también por el papel que desempeñan en el desarrollo económico. La sustentabilidad se asegura utilizando los recursos de forma que satisfagan las necesidades de las poblaciones sin comprometer las de las generaciones del futuro. La satisfacción de las necesidades de los pobres del mundo implica limitar el uso actual de recursos que hacen las naciones industrializadas. También hay que estabilizar el crecimiento de las poblaciones en los países menos desarrollados, ya que el desarrollo de recursos no se mantiene al mismo ritmo con que crece la población, lo que hace aumentar la pobreza. Por su parte, el deterioro ambiental aumenta los costos del desarrollo y el grado de pobreza. La desforestación, por ejemplo, produce erosión del terreno, inundaciones y deslizamientos del terreno, que reducen la productividad agrícola.

Hay numerosas formas de mejorar la salud de las poblaciones pobres. La tarea esencial es lograr que se satisfagan las necesidades básicas humanas de abrigo, aire limpio, agua potable segura y nutrición adecuada. Otros enfoques entrañan reducir las barreras que impiden la adopción de modos de vida más sanos y mejorar el acceso a servicios sociales y de salud apropiados y efectivos. Como clínicos, educadores, científicos que investigan y partidarios de cambios de política, los médicos pueden hacer aportes en todos esos campos. Ellos y otros profesionales de la salud deben comprender la pobreza y sus efectos en la salud de las poblaciones y tratar de ejercer influencia en los encargados de las decisiones políticas a nivel nacional e internacional para disminuir la carga de enfermedad que resulta de la pobreza. Los médicos tienen la responsabilidad profesional y moral de cuidar a los enfermos y evitar el sufrimiento. Puesto que se trata de una amenaza para la salud individual y colectiva, tienen también la responsabilidad social de tomar acción contra la pobreza y sus consecuencias para la salud. Ya es hora de que en la capacitación de estudiantes de medicina se insista en que conozcan los factores socioeconómicos de los pacientes, su grado de escolaridad, historia ocupacional, condiciones de vivienda y de contactos sociales, etc. para que hagan diagnósticos más completos y prescriban tratamientos más apropiados a las circunstancias individuales. En la comunidad, los médicos pueden abogar por políticas públicas que mejoren la salud de los marginados. Como investigadores, pueden dar a conocer los mecanismos que llevan de la privación a la mala salud y favorecer intervenciones eficaces para reducir la desigualdad en el acceso a servicios de salud. Pueden, igualmente, declararse a favor de que se perdone la deuda externa a los países más pobres. Además, podrían ayudar a hacer desaparecer las barreras que obstaculizan los estados de vida sanos pronunciándose contra el uso de tabaco y otras sustancias nocivas y la publicidad correspondiente. En cuanto al ambiente, los médicos deben apoyar legislación para mantener la calidad del aire, el agua y los alimentos. Los colegios y otros grupos de profesionales tendrían mucha influencia en actividades que se orienten a reducir las desigualdades de salud debidas a la pobreza. (McCally M, Haines A, Fein O, Addington W, Lawrence RS, Cassell CK. Poverty and ill health: physicians can, and should, 
make a difference. Ann Intern Med 1998;129(9): 726-733.

\section{Cinterandes: la cirugía llega a las zonas rurales del Ecuador}

En el Ecuador, país de apenas 12 millones de habitantes, la presencia de buenos recursos naturales no ha impedido que con cada nuevo gobierno haya crecido más y más la gran brecha que existe entre ricos y pobres. La proporción de la población que vive en la pobreza aumentó de $54 \%$ en 1990 a $63 \%$ en 1995 , pero se estima que en las zonas rurales del Amazonas y de La Sierra 76\% viven en extrema privación. Las tasas de alfabetización son más altas en la población de habla hispana que en la indígena y, si bien $49 \%$ de los niños de todo el país padecen desnutrición crónica, el porcentaje puede llegar a $70 \%$ entre los grupos autóctonos.

En el país coexisten diversos sistemas de salud: los seguros de enfermedad particulares cubren aproximadamente a $10 \%$ de la población, que representa la porción más adinerada; cerca de $20 \%$, por lo general empleados públicos y de empresas privadas, cuentan con la seguridad social; y $70 \%$, los menos privilegiados, reciben cobertura del Ministerio de Salud. Sin embargo, dos terceras partes de los médicos y hospitales están concentrados en las dos ciudades más grandes, Quito y Guayaquil, donde vive solamente una cuarta parte de la población del país. En las zonas rurales, los servicios de salud están a cargo de hospitales pequeños y centros de salud que, por lo general, no tienen personal suficiente, están mal equipados y no pueden responder adecuadamente a las necesidades de la población. Hay varias organizaciones no gubernamentales que trabajan en el Ecuador para complementar los servicios del Ministerio de Salud. Hace ya algunos años que una de ellas, Cinterandes, fundación radicada en la ciudad de Cuenca, trabaja para aminorar esa brecha entre ricos y pobres. El fundador y presidente de Cinterandes, Edgar Rodas, fue elegido Ministro de Salud en agosto de 1988. Una de las actividades de la Fundación es un programa de cirugía ambulante que desde 1994 ha estado brindando servicios de calidad a los habitantes de lugares remotos. La cirugía se lleva a cabo en la unidad quirúrgica itinerante de un camión que mide 24 pies de largo y que contiene un quirófano bien equipado y otro cuarto para el lavado del personal y la preparación de instrumentos.

Este programa se creó para responder a los muchos pacientes que requerían atención y a la falta de lugares donde obtenerla. El programa de Cinterandes está dirigido a pacientes ambulatorios y a personas que requieren operaciones más complejas y más tiempo de recuperación. Estos se quedan dos o tres días bajo observación en centros de salud rurales. Desde que comenzó sus actividades, en este programa se han realizado más de 2000 operaciones. Las más comunes son de cirugía menor, pero se llevan a cabo operaciones mayores cuando los pacientes están cerca de algún lugar donde pueden recibir cuidados postoperatorios. El equipo está constituido por cirujanos, anestesiólogos y personal de enfermería y de apoyo. Los pacientes son preseleccionados por médicos de la localidad adonde se dirige el equipo de Cinterandes, el cual evalúa y examina a los pacientes para determinar cuáles se beneficiarán más de la intervención. El equipo hace visitas de seguimiento de los pacientes en las primera y sexta semanas y 12 meses después de la operación. Los médicos y otro personal de salud local cooperan en el cuidado postoperatorio de los pacientes. La participación de la comunidad tiene un papel importante en este proceso y comprende desde el cuidado postoperatorio hasta la facilitación de enlaces con otros servicios de salud local y programas.

Además de la cirugía, el equipo Cinterandes educa a los pacientes y sus familiares, adiestra a residentes de anestesia y cirugía y a estudiantes de medicina de Cuenca y de países extranjeros, especialmente de los Estados Unidos. Además, los estudiantes participan en proyectos de investigación sencillos, especialmente sobre técnicas de cirugía, opciones frente a la anestesia y costo-eficacia. El programa ha tenido gran éxito gracias a la baja frecuencia de complicaciones, el ahorro de gastos comparados con los de los hospitales y las ventajas que tiene llevar la atención quirúrgica a esas zonas del país. El gobierno ha creado en Cuenca una unidad similar para el Seguro Social Campesino y hay otra parecida en Honduras, creada en 1995 por conducto de la OPS y la OMS. El énfasis de este programa en la comunidad y los buenos resultados que ha tenido lo han convertido en un modelo para otras situaciones, como los casos de desastre, $\mathrm{u}$ otros lugares del mundo en desarrollo. (Chella C. Bringing surgery to the rural areas of Ecuador. Lancet 352:715.)

\section{Aumenta el uso de medicinas "alternativas" en los Estados Unidos}

En 1990 se realizó en los Estados Unidos una encuesta de 1539 personas adultas, que mostró la alta prevalencia del uso de tipos de medicina llamada alternativa, complementaria, integral o no convencional. Esta nomenclatura se refiere a intervenciones terapéuticas que no se suelen enseñar en las escuelas de medicina del país ni hallarse disponi- 
bles en los hospitales. Su creciente popularidad en los últimos años ha llamado la atención de la comunidad médica, los organismos gubernamentales, los medios de comunicación y el público en general. Para documentar esa tendencia, en 1997 se efectuó otra encuesta con 2055 participantes. Los puntos de interés fueron la prevalencia, los costos estimados y la revelación por parte de los pacientes del uso de esas terapias a los médicos clínicos. Los resultados indicaron que entre 1990 y 1997 había aumentado de 33,8 a $42,1 \%$ el uso de hierbas medicinales, masajes, megavitaminas, grupos de autoayuda, remedios folkóricos, terapia de energía y homeopatía. La probabilidad de acudir a un practicante de medicina alternativa se incrementó de 36,3 a $46,3 \%$ ( $P=$ $0,002)$. En ambas encuestas se descubrió que esos tipos de medicina se buscan principalmente para las enfermedades crónicas, como los dolores de espalda, la ansiedad, la depresión y los dolores de cabeza. No se detectó ningún cambio significativo en cuanto a la frecuencia con que se informó de ese uso a los médicos de cabecera: 39,8 en 1990 frente a 38,5 en 1997. Tampoco hubo un cambio significativo en la proporción de personas que estuvieron de acuerdo con pagar esos servicios totalmente de su bolsillo: 64 y 58,3\%, respectivamente.

La extrapolación de los resultados de la segunda encuesta a la población estadounidense sugiere que el aumento de visitas a practicantes de medicina alternativa correspondió a la diferencia entre 427 millones de consultas en 1990 y 629 millones de consultas en 1997, lo que sobrepasa el total de consultas con todos los médicos de atención primaria del país. Se estima que 15 millones de adultos en 1997 tomaron medicamentos prescritos por médicos a la misma vez que remedios hechos de hierbas medicinales y altas dosis de vitaminas $(18,4 \%$ de todos los usuarios de prescripciones). Los gastos invertidos en servicios profesionales por tratamientos alternativos aumentó $45,2 \%$ entre las encuestas y una estimación conservadora indica que ascendieron a US\$ 21200 millones en 1997, de los cuales por lo menos $\$ 12200$ millones fueron pagos directos del bolsillo individual. Esa cantidad es mayor que todos los gastos pagados directamente por el usuario por todas las hospitalizaciones habidas ese año en los Estados Unidos. El total de pagos directos por terapias alternativas puede estimarse conservadoramente en $\$ 27000$ millones, cantidad comparable con los pagos directos de todos los servicios recibidos de médicos y proyectados para el 1997. Los aumentos en el uso de medicina alternativa registrados por medio de la encuesta más reciente se debieron a un mayor número de usuarios y no a un mayor número de visitas por paciente. Frente a esta realidad, algunas compañías de seguros y sistemas de gestión de los servicios han empezado a ofrecer programas y beneficios de medicina alternativa. Las encuestas nacionales realizadas en otros países muestran que no se trata de un fenómeno exclusivamente estadounidense. De la población de Dinamarca, $10 \%$ empleaba la medicina alternativa en 1987, 33\% de los finlandeses se valían de ella en 1982 y 49\% de los australianos, en 1993. En 1995, $15 \%$ de la población canadiense consultaba con practicantes de medicina alternativa. Otras encuestas revelan altas prevalencias de uso en toda $\mathrm{Eu}_{-}$ ropa y el Reino Unido.

El perfil de los usuarios de la medicina alternativa en los Estados Unidos resultó ser muy variado, si bien las mujeres $(48,9 \%)$ la usaron con mayor frecuencia que los hombres $(37,8 \%)(P=$ $0,001)$. Fue menos común entre los afroamericanos que en otros grupos étnicos y más común en el grupo de edad de 35 a 49 años, en las personas que tenían una educación universitaria por lo menos parcial y en las de altos ingresos. La mayoría de los usuarios recibieron terapia mediante masajes, quiropráctica, hipnosis, biorretroinformación y acupuntura. Sin embargo, el aumento de la prevalencia del uso se debió también a un mayor número de tratamientos en terapia de relajamiento, autoayuda y terapia de energía. En vista del gran número de personas que usan la medicina alternativa y las grandes cantidades de dinero que pagan por ello, los investigadores han recomendado que los organismos federales, las corporaciones privadas, las fundaciones y las instituciones académicas se ocupen de desarrollar investigaciones, planes de estudio y normas para la obtención de credenciales por profesionales, así como de controlar mejor los suplementos alimentarios y vigilar la interacción entre medicamentos y remedios basados en hierbas medicinales. (Eisenberg DM, Davis RB, Ettner SL, Appel S, Wilkey S, Van Rompay $M$, et al. Trends in alternative medicine use in the United States, 1990-1997.)

\section{El sida en los años noventa}

Actualmente el modelaje y el rastreo de la epidemia de sida está bajo la coordinación del Programa Conjunto de las Naciones Unidas sobre el $\mathrm{VIH} /$ Sida (ONUSIDA) y la OMS, que trabajan con redes de investigadores y programas nacionales de todo el mundo. Las fuentes de datos sobre la infección por virus de la inmunodeficiencia humana (VIH) y el sida han mejorado notablemente en muchos países. Se han quedado muy atrás las proyecciones sobre la epidemia que se hicieron tentativamente en 1988, de que el número de casos de sida podría llegar hasta los dos o tres millones a media- 
dos de los años noventa. A medida que nos acercamos al final de los noventa, se destacan tres puntos de contraste con las condiciones y los conocimientos de hace 10 años.

El primer punto se refiere a las condiciones; la amenaza que el VIH/SIDA representa para el mundo es mucho más grave de lo previsto. La epidemia está mucho más difundida de lo esperado, es considerablemente más compleja y ha resultado en una mortalidad varias veces más alta que lo que se había pensado. En el ámbito mundial, cerca de 12 millones de personas ya han muerto de sida y hay tres veces ese número de personas infectadas por el virus. A menos que se encuentre una cura, la mayoría de estas personas morirán durante el próximo decenio.

En segundo lugar, afortunadamente, en los últimos 10 años ha mejorado mucho la comprensión de lo que alimenta la epidemia y también de lo que puede hacerse en materia de prevención. En algunos lugares del mundo, este conocimiento se ha puesto en práctica con resultados promisorios. En otros, donde las lecciones no se han aprendido o la falta de información o de recursos han impedido su aplicación, la epidemia continúa creciendo. Por otra parte, también han mejorado los métodos de recoger datos y de modelarlos, en gran medida gracias a un mayor compromiso político y mejor cooperación técnica entre gobiernos y organizaciones internacionales.

Tercero, mientras que la prevención todavía es la respuesta más efectiva, se han elaborado métodos terapéuticos que alargan la vida, lo cual cambia nuestras perspectivas sobre el futuro de la epidemia. La relación entre nuevas infecciones, niveles de prevalencia, incidencia del sida y mortalidad ya no son tan fáciles de predecir como lo eran anteriormente. No obstante, el alto costo de los medicamentos significa que ha de pasar algún tiempo antes de que en los países en desarrollo se detecten efectos significativos de esas formas de terapia. Lamentablemente, esa lentitud afectará principalmente a los países donde es mayor la incidencia de infección por VIH.

Se cree que en América Latina y el Caribe alrededor de 1,3 millones de personas tienen sida o infección por VIH. La forma en que se extiende la epidemia en esas regiones es similar a la observada en los países industrializados. Los puntos focales de la infección son los hombres que tienen relaciones sexuales desprotegidas con otros hombres, y quienes se inyectan drogas y comparten las agujas y jeringas con otras personas. El aumento de las tasas de infección entre las mujeres indica que la transmisión heterosexual es cada vez más importante. En el Brasil, una cuarta parte de los 550000 adultos con la infección son mujeres, pero en toda la Región de las
Américas la proporción de mujeres infectadas es de una quinta parte. De las mujeres embarazadas en Honduras, $1 \%$ tienen la infección por VIH. La proporción llega al 3\% en Porto Alegre, Brasil. En el Caribe las tasas son mucho más altas.

Nota: Estos datos provienen del informe publicado en junio de 1998 por OMS/ONUSIDA sobre la epidemia mundial de VIH/sida. El informe completo se puede obtener de la Internet en la siguiente dirección: http:/www.unaids.org/highband/fact/ index.html. (Schwartlander B, Sittitrai W. Commentary: HIV / AIDS in the 1990s and beyond. Bull World Health Organ 1998;76(5):437-443.)

\section{Tratamiento combinado con HAART e interleucina 2 contra los VIH "escondidos"}

Las personas tratadas con interleucina 2 (IL-2) más terapia antrirretrovírica intensa (HAART, por el inglés highly active antiretroviral therapy) tienen muchos menos linfocitos T CD4+ inactivos infectados con virus de la inmunodeficiencia humana (VIH) en el torrente sanguíneo que los pacientes tratados con HAART exclusivamente. Estos resultados, procedentes de un ensayo clínico controlado en 26 pacientes del Instituto Nacional de Alergias y Enfermedades Infecciosas (NIAID) de los Estados Unidos de América, demuestran la eficacia de ese régimen combinado para penetrar en los linfocitos CD4+ inactivos, donde el VIH puede permanecer latente por años incorporado a los genes celulares, aun en pacientes que reciben tratamiento medicamentoso intenso a base de tres fármacos.

Los pacientes recibieron HAART, que consiste en dos medicamentos antirretrovíricos más un inhibidor de las proteasas, ó HAART combinado con IL-2 intravenosa o subcutánea. La IL-2, proteína reguladora del sistema inmunitario producida en el organismo, estimula la proliferación, diferenciación y actividad de diversas células inmunitarias, especialmente de los linfocitos $\mathrm{T}$ que la producen. Las dosis de IL-2 variaron de 3 a 18 millones de unidades internacionales diarias administradas en ciclos de 5 días separados por un período mínimo de descanso de 8 semanas entre ciclos. En la primera muestra de sangre todos los 26 pacientes tuvieron cargas víricas de menos de 50 copias de VIH por mililitro $(\mathrm{mL})$ de sangre.

En seis de los 14 pacientes tratados con HAART más IL-2, los investigadores no pudieron detectar VIH capaces de replicarse en cultivos de sangre periférica de 10 a 20 millones de linfocitos CD4+ inactivos. Tampoco los encontraron en tres de estos pacientes cuando el cultivo de células CD4+ inactivas ascendió a 330 millones. Se tomó una biop- 
sia de nódulo linfático a uno de estos tres pacientes y el resultado fue negativo para la presencia de VIH viables. En cambio, los 12 pacientes que recibieron HAART exclusivamente tuvieron VIH capaces de replicarse en los linfocitos CD4+ cultivados en la sangre periférica. Se cree que la IL-2 reduce el "reservorio" de VIH que, al estar secuestrados dentro de los linfocitos inactivos, pueden permanecer fuera del alcance del sistema inmunitario.

Algunos expertos creen que hay otros reservorios de VIH en el organismo, tales como el cerebro, los testículos, los linfocitos CD4+ de los intestinos y otros órganos linfoideos, y en otros tipos de células inmunitarias, entre ellas los macrófagos. Aunque esto representa una barrera hasta ahora infranqueable para la erradicación o el control de VIH en el organismo de una persona infectada, varios investigadores se esfuerzan por encontrar maneras de reducir la carga de VIH "escondidos" y de esa forma dar al sistema inmunitario del huésped la oportunidad de combatir la infección.

Aún falta determinar los mecanismos que llevan a los resultados observados con HAART más IL-2 y determinar la importancia clínica de reducir la carga de VIH en células con infección latente. La factibilidad de controlar la presencia dentro de estas células de VIH capaces de replicarse quedará confirmada cuando se pueda prescindir de HAART y del seguimiento del paciente a largo plazo. (National Institutes of Health, National Institute of Allergy and Infectious Diseases. Treatment with IL2 plus HAART markedly reduces HIV in immune system "hiding places." NIH News Realease, Sunday, November 15, 1998.)

\section{La terapia celular: algunas consideraciones}

La terapia celular, usada para sustituir o reparar la función de células o tejidos lesionados, consiste en transplantar células individuales a un órgano receptor en cantidades suficientes para que sobrevivan y restauren la función normal. La mayor parte de las células tisulares provienen de formas precursoras inmaduras que se diferencian hasta poder llegar a desempeñar las funciones que les exige su entorno inmediato. El organismo reemplaza los tejidos en degeneración de dos maneras: 1) por diferenciación de células nuevas a partir de precursoras residuales, como en el caso de las células sanguíneas, y 2) por proliferación de células ya diferenciadas, como sucede con las células hepáticas, endoteliales y de músculo esquelético. Actualmente se cree que hay células primordiales en estado latente en la mayor parte de los tejidos del adulto, pero que son escasos los estímulos que las activan. La mayoría de las enfermedades o lesiones que alteran la función celular son, sin embargo, demasiado graves para ser corregidas por estos mecanismos de autorreparación. En tales casos es factible acudir a la terapia celular, eligiendo la célula que ha de injertarse según el tipo de lesión tisular y la función que deberá desempeñar la célula transplantada.

Pueden transplantarse células con el propósito de que secreten determinadas sustancias solubles con efectos locales o sistémicos. En otros casos, las células implantadas deben desempeñar funciones fisiológicas definidas. Por consiguiente, su fenotipo y espaciamiento cobran gran importancia desde el punto de vista de su utilidad. La terapia celular se ha aplicado con mioblastos en casos de distrofia muscular; con epitelio retineano en pacientes con degeneración macular y con tejido neuronal en pacientes con parkinsonismo. En un futuro se espera poder aplicarla con hepatocitos en pacientes cirróticos. Por último, en algunos casos las céulas implantadas deberán desempeñar funciones muy complejas de reparación o sustitución de tejidos para las cuales su localización espacial y temporal tendrá una importancia crítica. El principal ejemplo de este tipo de terapia es el reemplazo continuo y completo del tejido hematopoyético mediante el transplante de médula ósea.

A la hora de decidir qué tipo de célula se debe transplantar, se suman a los factores anteriores ciertas propiedades de las células mismas, como su accesibilidad y la rapidez y facilidad con que se cultivan, multiplican y manipulan. También es un factor limitante la cantidad de células necesaria para lograr la función deseada. Algunas células no pueden regenerarse in vitro. En tales casos se debe considerar el uso de células no autólogas, como las alógenas, las inmortalizadas o las xenógenas. Una de las principales ventajas de las células alógenas es que no hay que esperar hasta que haya donantes, ya que las células pueden prepararse mucho antes del transplante. No obstante, están sujetas a los mismos problemas de variabilidad y replicabilidad que afectan a las células autólogas. Las líneas celulares primarias proliferan con dificultad, aunque pueden clonarse y subclonarse hasta lograr una línea sin esta desventaja. Por otra parte, las células inmortalizadas o transformadas a menudo pierden su capacidad de diferenciarse por completo y pueden convertirse en células neoplásicas después de injertarse. Pero el peor problema que plantean las células no autólogas es su capacidad para inducir un respuesta inmunitaria que las destruya. En el caso de las células alógenas, la reacción suele estar mediada por linfocitos T. La respuesta inmunitaria puede mitigarse mediante el uso de células derivadas de poblaciones 
puras sin contaminación con leucocitos o células endoteliales y procurando producir poca lesión al sitio del injerto.

No hay, en efecto, ninguna célula ideal que llene todos los requisitos para combatir cualquier enfermedad. Las células obtenidas de donantes no solo plantean los problemas inmunitarios descritos, sino también algunos de carácter ético. Deben someterse a pruebas de inocuidad antes de usarse en seres humanos. Se recomienda, por ejemplo, efectuar pruebas de integridad cromosómica, de esteri- lidad y de detección de micoplasmas y diversos virus, tales como los VIH 1 y 2. También debe investigarse la inocuidad del procedimiento quirúrgico empleado.

En resumen, la terapia celular requiere un enfoque que abarca muchas disciplinas, desde la inmunología hasta la biología celular, y su éxito se basa en poder entender la complejidad de la interacción entre la célula individual y el organismo huésped. (Gage FH. Cell therapy. Nature 1998;392 (supl):18-24.).

\section{Ganador del premio Fred L. Soper en Salud Interamericana, 1998}

La Junta de Directores de la Fundación Panamericana de la Salud (PAHEF) anunció recientemente que el premio Fred L. Soper en Salud Interamericana para 1998 ha sido adjudicado a Joaquim Noroes y sus colaboradores, G. Dreyer, A. Santos, V.G. Mendes, Z. Medeiros y D. Addiss, por su artículo "Assessment of the efficacy of diethylcarbamazine on adult Wuchereria bancrofti in vivo", que se publicó en la revista Transactions of the Royal Society of Tropical Medicine and Hygiene (1997, volumen 91, pp. 78-81).

La PAHEF se encarga de administrar este premio, que se concede anualmente en honor del doctor Fred L. Soper, ex Director de la OPS (1947-1958), por un trabajo científico publicado que aporte conocimientos originales al campo de la salud pública de América Latina y el Caribe. La Revista Panamericana de Salud Pública/Pan American Journal of Public Health se complace en felicitar calurosamente a los galardonados. 